\title{
The effect of residual lignin on the rheological properties of cellulose nanofibril suspensions
}

\author{
Maria C. Iglesias ${ }^{\mathrm{a}}$, Niloofar Shivyari ${ }^{\mathrm{b}, \mathrm{c}}$, Ann Norris ${ }^{\mathrm{b}, \mathrm{c}}$, Raquel Martin-Sampedro ${ }^{\mathrm{d}, \mathrm{e}}$, M. E. Eugenio ${ }^{\mathrm{d}}$, Panu \\ Lahtinen $^{f}$, Maria L. Auad ${ }^{g}$, Thomas Elder ${ }^{\mathrm{h}}$, Zhihua Jiang ${ }^{\mathrm{g}}$, Charles E. Frazier $^{\mathrm{b}, \mathrm{c}}$, and Maria S. Peresin ${ }^{\mathrm{a}}$ \\ ${ }^{a}$ Forest Products Development Center, School of Forestry and Wildlife Sciences, Auburn University, Auburn, Alabama, USA; \\ ${ }^{\mathrm{b}}$ Sustainable Biomaterials, Virginia Tech, Blacksburg, Virginia, USA; 'Macromolecules Innovation Institute, Virginia Tech, Blacksburg, \\ Virginia, USA; ${ }^{d}$ National Institute of Agricultural and Food Research and Technology (INIA), Spain; ${ }^{e}$ Material Science Institute of \\ Madrid (ICMM-CSIC), Spain; ${ }^{f}$ VTT Technical Research Centre of Finland, Espoo, Finland; ${ }^{9}$ Department of Chemical Engineering, Samuel \\ Ginn College of Engineering, Auburn University, Auburn, Alabama, USA; ${ }^{\text {h}}$ Southern Research Station, U.S. Forest Service, U.S. \\ Department of Agriculture, Auburn, Alabama, USA; 'Alabama Center for Paper and Bioresource Engineering, Auburn University, \\ Auburn, Alabama, USA
}

\begin{abstract}
Although the removal of lignin and hemicelluloses from cellulose pulp to produce fully bleached cellulose nanofibrils (B-CNF) is the most common practice, the presence of residual lignin and hemicelluloses in raw materials for the production of lignin containing cellulose nanofibrils (LCNFs) holds several advantages. In this work, we investigated the effect of residual lignin in Eucalyptus globulus cellulose fibers on the properties of the resulting LCNFs. The stability of the colloidal suspensions was assessed by zeta-potential values and charge density analyses. Morphology of the CNFs was studied using scanning electron microscopy and atomic force microscopy. Fibril diameter and diameter distributions for CNFs with different levels of residual lignin showed a decrease on fiber diameter as the lignin content increases. Differences in the chemical composition of the CNFs was evidenced as indicated in the Fourier-transform infrared spectroscopy spectra, particularly in fingerprint region. Thermal behavior of the CNFs was not altered by the presence of lignin, as indicated by thermogravimetric analysis. Finally, the rheological behavior of the samples was evaluated observing a gel-like behavior as well as an increase of the viscosity in LCNFs with higher lignin contents.
\end{abstract}

\section{KEYWORDS}

Lignin-containing cellulose nanofibrils; LCNFs; rheology; residual lignin; lignonanofibers; cellu-

losic nanofibers

\section{Introduction}

As a result of the growing demand for sustainable, high-performance materials, significant advances has been made worldwide on the utilization of nanocellulose. Nanocellulose of various nature have been a research topic of interest for various applications such as paper coating, ${ }^{[1]}$ rheological modifier, ${ }^{[2]}$ packaging material with improved barrier properties, ${ }^{[3,4]}$ emulsion stabilizer, ${ }^{[5]}$ among others.

The two most important types of nanocellulose for which production processes and yields have been highly optimized over the years are cellulose nanocrystals (CNC) and cellulose nanofibrils (CNF). CNC is produced by acid hydrolysis of the less ordered regions of the cellulose fibers, resulting in lower yields than in the case of $\mathrm{CNF}^{[6]}$ that are primarily obtained by mechanical treatment. The drawback of the latest being the high energy consumption of the process. ${ }^{[7]}$

Currently, a large proportion of CNF grades are produced from fully bleached chemical pulps that contain only trace amounts of residual lignin $(<1 \%)$ and hemicelluloses. Although a few companies around the world such as Borregaard, CelluForce Inc., CelluComp Inc., Chuetsu Pulp \& Paper Co. Ltd, Daio Paper Corporation, and DKS Co. Ltd. are currently commercializing nanocellulosic materials from fully bleached raw materials, significant developments have been done utilizing lignin-containing fibers as starting material for CNF production. Unbleached fibers offer the advantage of higher yields (in terms of polysaccharide content) and reduced processing cost and environmental burden by avoiding bleaching steps. ${ }^{[4]}$ 
Additionally, remaining lignin and hemicelluloses on the fibrils represents an interesting alternative for many applications due to the attractive properties conferred to the final material. ${ }^{[8,9]}$ The hydrophobic nature of lignin, allows for better compatibility with nonpolar media and matrices, improving the mechanical and barrier properties of LCNF-reinforced composites. $^{[10]}$ Even though appealing, the effect of residual lignin on the fibrillation process still remains unclear. There is significant controversy regarding whether the presence of lignin aids or impedes the mechanical separation of the individual fibrils in the plant cell wall. Some researchers have reported that the presence of lignin improves the defibrillation process, ${ }^{[11]}$ and also that the additional presence of hemicelluloses increase the surface charge of the fibrils, resulting in repulsion between the fibrils, allowing an easier separation from each other. ${ }^{[4]}$ On the opposite, other researchers claim that the significant reduction on surface charge on LCNF due to the presence of lignin ends up hindering fibrillation. ${ }^{[12]}$

During the last few years, more efforts have been directed toward the incorporation of LCNFs in different composite materials, employing a diverse number of matrices such as polycaprolactone, ${ }^{[13]}$ polypropylene, ${ }^{[14]}$ polystyrene, ${ }^{[15]}$ among others. Characterizing LCNF is essential for understanding not only the structure of the colloidal suspensions, but also the fibrils interactions with the surrounding media that in turn, will determine the properties of the final product. Moreover, rheological properties are highly relevant since knowing the flow characteristics of the material can be very useful during handling and processing. ${ }^{[16]}$

In the last few decades researchers have studied the rheology of micro- and nano-scale cellulose fibrils (MFC and CNF, respectively) obtained by varying routes, e.g., by enzymatic treatments, ${ }^{[17]}$ from different raw materials ${ }^{[18,19]}$ or by applying different treatments, such as carboxymethylation of the fibers. ${ }^{[20]}$ It is worth mentioning that rheological characteristics of nanocellulose are mainly related to their intrinsic properties, such as the dimension and shape of the elements (rod-like structures for $\mathrm{CNC}$ and fibrillar structures for $\mathrm{CNF}$ ), how branched or crystalline the structures are, and the surface charges of the nanoparticles. ${ }^{[21]}$

As a general rheological behavior, it has been reported that $\mathrm{CNF}$ aqueous suspensions follow a shear-thinning behavior. ${ }^{[17,22,23]}$ Shear-thinning is a nonlinear phenomenon in which the viscosity of the material decreases with increasing shear rate () due to the motion of the fibrils chains, surrounded by other fibrils. Thus, when a deformation is applied, particles aggregates can be disrupted allowing the movement of the fibrils in one direction, along their axis. ${ }^{[24]}$ Orientation of the nanoparticles during flow of the suspension is an important consideration since they can agglomerate, align or even form networks that will have a direct impact on their viscosity. ${ }^{[25]}$

The most common physical aspects affecting the rheological properties of CNF are solid content, temperature, $\mathrm{pH}$, morphology, and surface charge. ${ }^{[17,26,27]}$ The effect of the solid content on the viscosity can be explained by analyzing the entanglements of the fibers. $^{[2,28]}$ Higher concentrations of the suspensions result in more entangled structures which increases the contact points between fibrils; the more bonds among the fibrils, the higher the viscosity. ${ }^{[27]}$ An additional change in the viscosity can be achieved by modifying the temperature of the system. This additional energy introduced on the structure is able to break down some bonds between the fibers resulting in decreased viscosity of the suspension. ${ }^{[27]}$ Regarding the $\mathrm{pH}$ of the slurries, it has been proven that $\mathrm{pH}$ significantly affects the rheological properties of $\mathrm{CNF}$ suspensions. ${ }^{[17]}$ The effect of charge density over bleached cellulose nanofibrils regarding their rheological behavior has also been studied, showing an increase in the viscosity as the charge density increases. ${ }^{[29]}$

In this work, we analyzed the rheological behavior of LCNFs -obtained from Eucalyptus pulp with different contents of residual lignin- through steady-state and oscillation modes. Divergence between samples was initially found as a result of different chemical compositions based on the amount of lignin and hemicelluloses present in the fibrils. Additionally, the LCNF suspensions were characterized in terms of charge density, chemical composition and morphology.

\section{Materials and methods}

\section{Materials}

For the purpose of this work, four different neverdried cellulose pulps were used. Eucalyptus globulus chips were supplied by La Montañanesa pulp mill (Torraspapel - Lecta Group, Spain), and the pulping process of the raw material was carried out by the National Institute of Agricultural and Food Research and Technology (INIA, Spain). Chemicals used during the pulping and bleaching process were purchased 
Table 1. Power-law parameters and regression values $\left(R^{2}\right)$ fitted to the data $\left(\eta=K^{n-1}\right){ }^{[47]}$

\begin{tabular}{lccc}
\hline Sample (lignin content) & $\mathrm{K}\left(\mathrm{Pa}^{*} \mathrm{~s}^{\mathrm{n}}\right)$ & $\eta$ & $R^{2}$ \\
\hline $0.6 \%$ & 11.511 & 0.267 & 0.9880 \\
$1.7 \%$ & 13.885 & 0.200 & 0.9909 \\
$4.7 \%$ & 37.463 & 0.145 & 0.9897 \\
$10.2 \%$ & 44.347 & 0.155 & 0.9937 \\
\hline
\end{tabular}

from Panreac (Barcelona, Spain) and Sigma-Aldrich (Madrid, Spain).

For charge density measurements, poly(diallyldimethylammonium chloride) (pDADMAC) solution and potassium polyvinyl sulfate (PVSK), both at $0.001 \mathrm{~N}$ concentration were acquired from BTG (USA). Polyethylenimine (PEI) was purchased from Sigma Aldrich (USA) and silicon oil for the rheological measurements was acquired from Fisher Scientific (USA).

\section{Methods}

\section{Pulping process}

A conventional kraft pulping was performed to acquire a set of four cellulose samples. ${ }^{[30]}$ Following to the pulping, bleaching steps were carried out when necessary, to obtain samples with different chemical composition, mainly lignin and hemicelluloses content. More detailed information about the pulping process can be found in Table S1, Supporting material.

\section{Pulp composition}

All pulps were characterized by standard analytical methods (National Renewable Energy Laboratory NREL/TP-510-42618) to determine hemicelluloses and lignin contents.

\section{LCNFS production}

Cellulose nanofibrils were produced at VTT Technical Research Center of Finland Ltd. (Espoo, Finland) using pulps $1,2,3$, and 4 as previously described in section "Pulping process". They were first diluted to approximately $1.8 \mathrm{wt} \%$ followed by a mechanical dispersion to avoid the formation of agglomerates. Next, the cellulose pulp in water was ground using a Supermasscolloider friction grinder MKZA10-15J (Masuko Sangyo Co., Fiber) by twice passing the suspension between one stationary and one rotating stone, allowing the break down and delamination of the fibers. These suspensions were then circulated through a Microfluidizer M7115-30 (Microfluidics Corporation) five times, allowing the fracture of the fibers into smaller portions. Gel-like nanocellulose suspensions were then obtained from all the samples.

\section{Characterization of LCNF suspensions}

Zeta-potential and charge density. The colloidal stability of the suspensions was assessed by performing charge density and zeta potential measurements. For this purpose, $\mathrm{pH}, \mathrm{Z}$-potential, and conductivity of the samples were measured using a SympHony Benchtop Multi Parameter Meter B30PCI (VWR®) equipped with $\mathrm{pH}$ and conductivity electrodes. Measurements were repeated 15 times and averaged. Zeta-potential and charge density were measured at $\mathrm{pH}=7$.

To assess the charge density of the fibers, a polyelectrolyte titration method was adapted from Espinosa et al. ${ }^{[31]}$ First, the LCNF were prepared into suspensions with a $0.04 \mathrm{wt} \%$ consistency, $\mathrm{pH} \mathrm{7,} \mathrm{and}$ sonicated for $10 \mathrm{~min}$ with a Vibra Cell sonicator (Newtown, CA) at $20 \mathrm{~kW}$ and $25 \%$ of amplitude to effectively disperse the fibers. Then, $25 \mathrm{ml}$ of pDADMAC were added and mixed with $15 \mathrm{ml}$ of the resulting LCNF suspensions using a magnetic stirrer for $30 \mathrm{~min}$, followed by $15 \mathrm{~min}$ of centrifugation at $3000 \mathrm{rpm}$. Thereafter, $10 \mathrm{ml}$ of the supernatant were separated and measured in a Laboratory Charge Analyzer Chemtrac LCA-1, (Norcross, GA). As anionic titrant, PSVK was used until a 0 streaming current value (SCV) was obtained. The volume consumed was then transform into charge density equivalents by Eq. (1).

$$
\begin{aligned}
& \text { Charge density } \\
& =\frac{\left([p D A D M A C] * V_{p-D A D M A C}\right)-\left([P V S K] * V_{P V S K}\right)}{W_{\text {dry LCNF sample }}}
\end{aligned}
$$

where $[p D A D M A C]$ is the solutions concentration of the cationic polymer, $V_{P D A D M A C}$ is the used volume of p-DADMAC added to the mix, $[P V S K]$ is the concentration of the stock anionic titrant, $V_{P V S K}$ is the used volume for the titration, and $W_{d r y}$ LCNF sample is the dry weight of the LCNF samples. Measurements were performed six times per each sample.

Thermogravimetric analysis

(TGA).

Thermogravimetric analysis was carried out to determine the thermal decomposition of the samples containing different amounts of lignin. Analyses were performed on a Perkin Elmer Pyris 1 TGA. Samples were preheated at $120^{\circ} \mathrm{C}$ for $20 \mathrm{~min}$ to eliminate the moisture content, ${ }^{[32]}$ after which the temperature was increased at $10^{\circ} \mathrm{C} / \mathrm{min}$ to $800^{\circ} \mathrm{C}$ in an argon atmosphere $(25 \mathrm{ml} / \mathrm{min})$. For the thermogravimetric 
a)

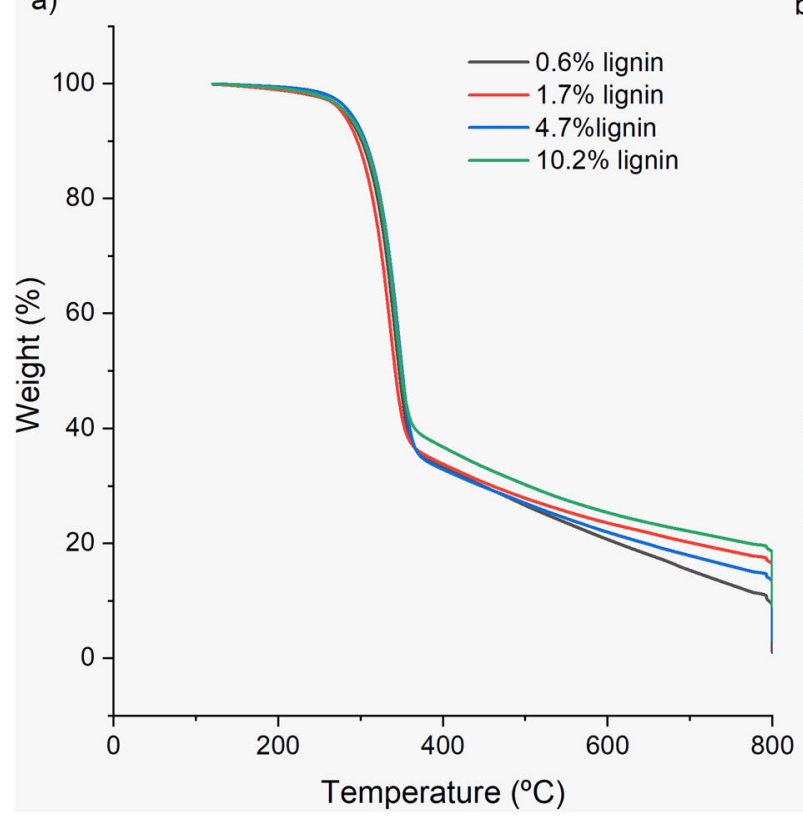

b)

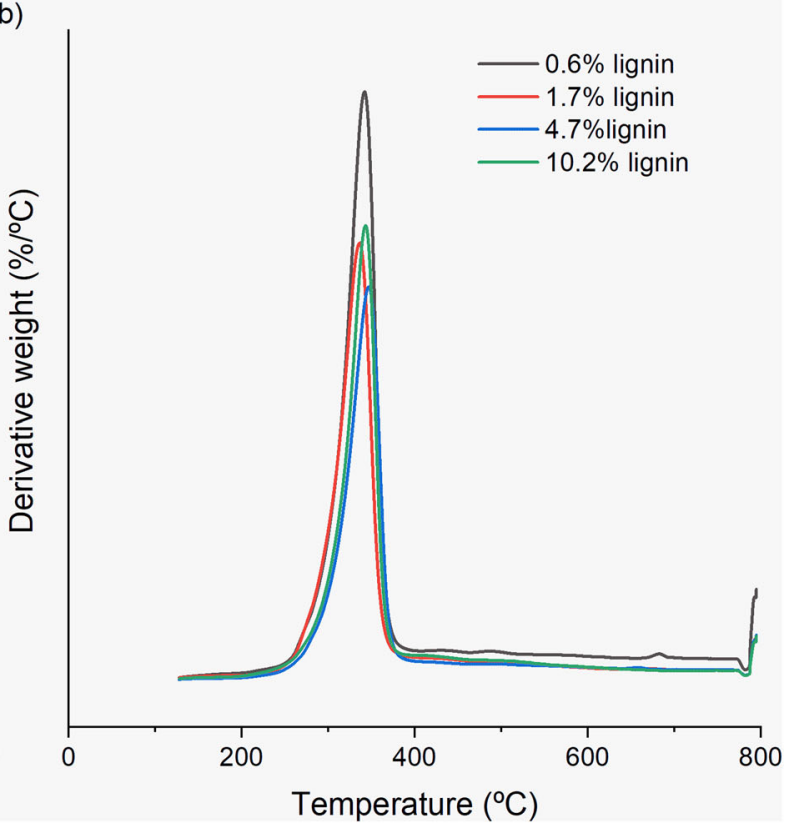

Figure 1. a) TGA spectra in argon and b) derivative weight of the LCNF containing $0.6,1.7,4.7$, and $10.2 \%$ of lignin.

analyses, samples were stabilized at $120^{\circ} \mathrm{C}$. Size of samples was approximately $15 \mathrm{mg}$ for all the LCNFs.

\section{Fourier-transform infrared spectroscopy with attenu-} ated total reflectance accessory (ATR-FTIR). To determine chemical and structural composition of the samples, ATR-FTIR analyses were performed using a PerkinElmer Spotlight 400 FT-IR Imaging System (Massachusetts, US) with an ATR accessory with diamond/ZnSe crystal. Before the measurements, a background spectrum was recorded for each different sample. Afterwards, all spectra were collected from 400 to $4000 \mathrm{~cm}^{-1}$ with a $4 \mathrm{~cm}^{-1}$ wavenumber resolution after 4092 continuous scans. The baseline was corrected, and the data was processed with Spectrum 6 Spectroscopy Software (PerkinElmer, MA, US).

Microscopy. The morphology of the samples was studied using field emission scanning electron microscopy (FE-SEM), and atomic force microscopy (AFM). LCNF suspensions were prepared at 0.1 and $0.01 \mathrm{wt} \%$ for SEM and AFM, respectively. The samples were sonicated using a Vibra Cell sonicator (Newtown, CA) for 10 min with $20 \mathrm{~kW}$ and $25 \%$ amplitude to promote delamination and prevent their agglomeration, with a cold bath to avoid heating of the samples.

For SEM imaging, a droplet was placed onto a silica wafer and air-dried for a few days. Before the measurement, surfaces were coated with a gold layer under an argon atmosphere using an EMS 550x Sputter Coating Device. SEM analyses were performed using a Carl Zeiss Supra 35VP SEM; images were taken with an accelerating voltage of $20 \mathrm{keV}$ at a working distance of $\sim 7 \mathrm{~mm}$.

For AFM imaging, before the LCNF deposition, silicon surfaces were cleaned using UV ozone for $30 \mathrm{~min}$ and submerged for $15 \mathrm{~min}$ into $0.1 \mathrm{wt} \%$ polyethylenimine (PEI) which was used as an anchoring solution. Images were obtained in tapping mode using a Bruker (formerly Digital Instruments, Veeco) AFM Dimension 3100 (CA, US). Amplitude images were obtained at $2.35 \mathrm{~Hz}$, and tip velocity of $23.4 \mu \mathrm{m} / \mathrm{s}$ using a Nano World (Innovative Technologies) FM 20 silicon SPM-sensor cantilever with resonance frequency of $75 \mathrm{kHz}$ and force constant of $2.8 \mathrm{~N} / \mathrm{m}$. Images were processed with Gwyddion software 2.49 (SourceForge). Size of all images was $5 \mu \mathrm{m} \times 5 \mu \mathrm{m}^{2}$.

The diameter of fibrils and fibers in each LCNF analyzed with AFM was determined by using the ImageJ software. ${ }^{[33]}$ One hundred measurements were taken per AFM image, and the results of the measurements were then classified in nine different groups, according to the size range. For each size group, an average size value and its standard deviation was calculated (results shown in Figure 1).

Rheological behavior. Rheological measurements were carried out with a stress-controlled rheometer AR2000 (TA Instruments, DE, USA) using $40 \mathrm{~mm}$ diameter parallel plate geometry and a constant temperature of $25^{\circ} \mathrm{C}$.

Prior to all measurements, LCNF suspensions were sonicated for $10 \mathrm{~min}$ using a $750 \mathrm{~W}$ Vibra Cell sonicator (CT, USA) with $20 \mathrm{~kW}$ and $25 \%$ amplitude. A 


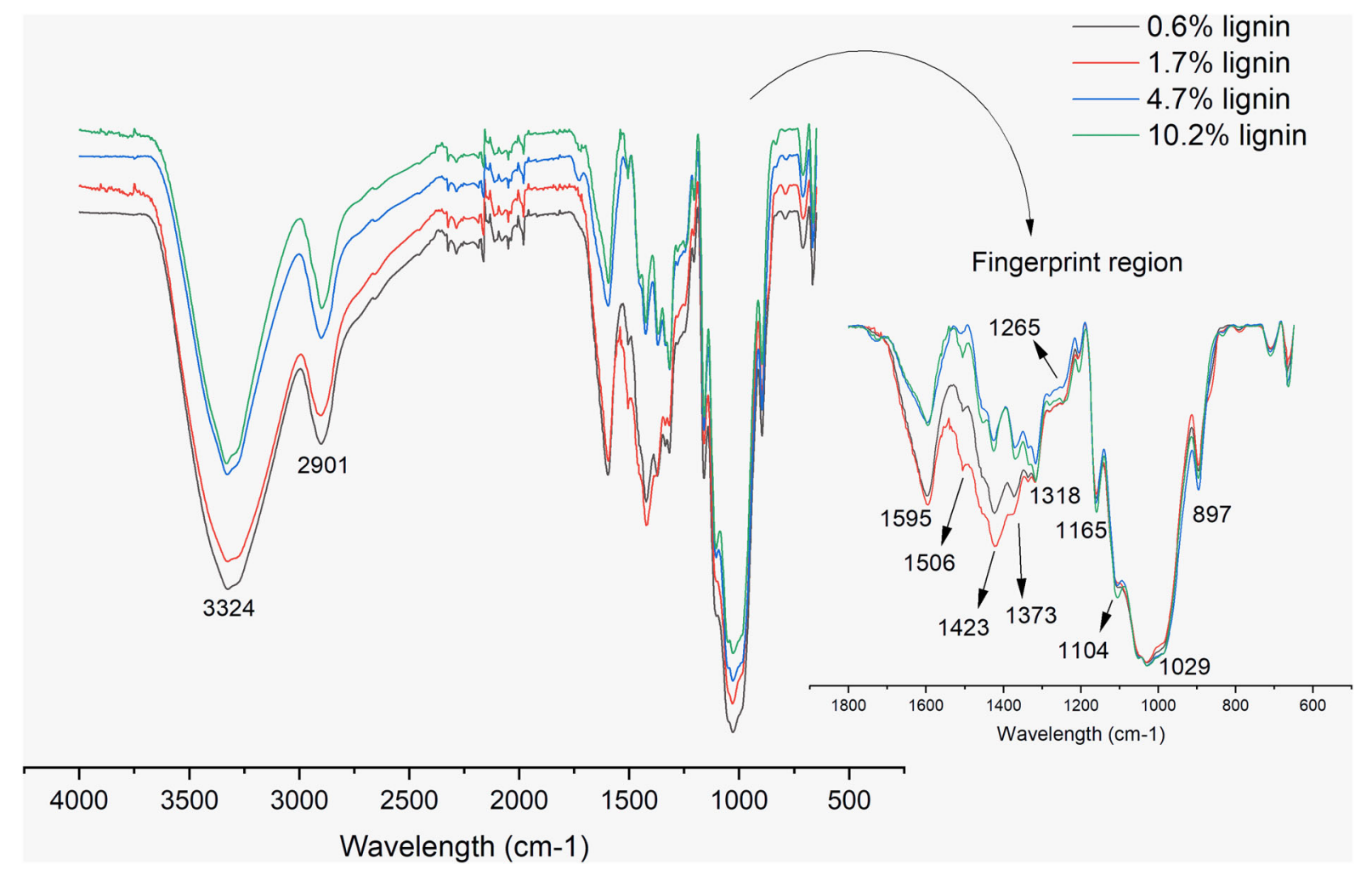

Figure 2. FT-IR spectra of the LCNF containing 0.6 (grey), 1.7 (red), 4.7 (blue), and 10.2\% of lignin (green).

cold bath was used to avoid over-heating the suspensions. All samples were thoroughly stirred using a spatula prior to loading. In all experiments, approximately $5 \mathrm{ml}$ of sample was loaded on the Peltier plate. The upper plate was lowered to $1050 \mu \mathrm{m}$ gap and excessive samples were trimmed-off. Final gap was set to be $1000 \mu \mathrm{m}$. At this gap, silicon oil was delicately applied around the parallel plate to seal the system and prevent water evaporation. When not in use, suspensions were kept in a fridge at all times to prevent any degradation. The consistency of all samples was $1.5 \mathrm{wt} \%$. All pH levels were adjusted to 7 .

As a preliminary experiment, a series of frequencysweep $(0.01-100 \mathrm{~Hz}$ at $5 \mathrm{~Pa})$ and stress-sweep (0.1-100 $\mathrm{Pa}$ at $1 \mathrm{~Hz})$ tests were carried out to identify the limits of the linear viscoelastic region (LVR), defining a limited frequency of $1 \mathrm{~Hz}$ where the sample showed a linear viscoelastic behavior. Subsequently, steady-state flow tests ( $5 \%$ tolerance) were performed at $1000 \mu \mathrm{m}$ gap with shear-rates ranging from 0.01 to $3000 \mathrm{~s}^{-1}$ to study the effect of lignin content on viscous behavior of suspensions. For these flow tests, a preshear of $100 \mathrm{~s}^{-1}$ was applied for $5 \mathrm{~min}$ to prevent fiber coagulation. Once the up-ramp flow curves were obtained, samples were allowed to relax for $10 \mathrm{~min}$ and down-ramp flow tests were performed from 0.01 to $3000 \mathrm{~s}^{-1}$. Measurements were performed in triplicate and then averaged.

\section{Results and discussion}

\section{CNF characterization}

\section{Charge density and colloidal stability of the suspensions}

Zeta-potential measurements give an indication of the stability of the colloidal suspensions. It is assumed that suspensions with a zeta-potential higher than $+30 \mathrm{mV}$ or lower than $-30 \mathrm{mV}$ are stable. ${ }^{[34]}$ Zeta potential for all LCNF samples, measured at the same $\mathrm{pH}$, was between -33 and $-38 \mathrm{mV}$ corroborating their colloidal stability.

Individual charge density values can be found in Table S2, Supporting material. A statistical Tukey test was carried out, indicating that only 1.7 and $10.2 \%$ lignin content samples were significantly different (see Figure S1, Supporting material). Similar behavior was reported by others, ${ }^{[12,35,36]}$ which observed that the absence of lignin tends to increase the surface charge density of the fibrils. This behavior could be explained by the higher adsorption of the cationic polymer due to the higher $\mathrm{OH}$ group availability on the fibril surface. Nevertheless, an opposite trend was reported by Solala et al. ${ }^{[1]}$ showing that as the lignin content of the samples increase, the charge density increase. These differences can be attribute to the different pulping process utilize during lignin removal. Sulfite process it is usually known as a better lignin removal 

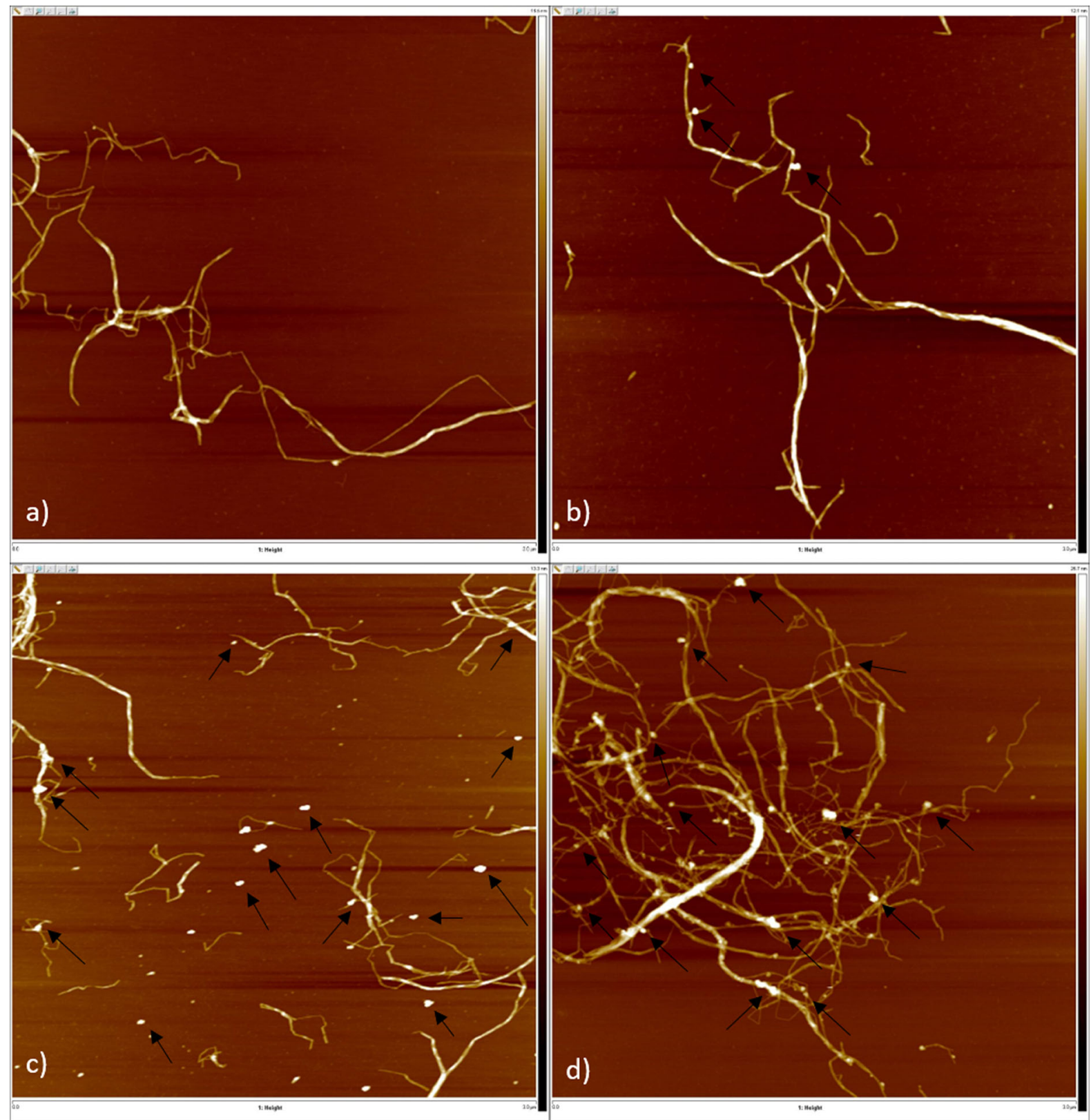

Figure 3. AFM topographic images of LCNF containing a) 0.6 , b) 1.7, c) 4.7 , and d) $10.2 \%$ of lignin.

when compared with the Kraft process. ${ }^{[37,38]}$ These differences will impact differently on the fiber superficial properties.

\section{Thermogravimetric analysis (TGA)}

Thermal decomposition and weight derivative are presented. Figure 1(a,b) respectively, from 120 to $800^{\circ} \mathrm{C}$.

It has been reported in the literature that lignin decomposes slower and over a broader range (between 160 and $900^{\circ} \mathrm{C}$ ) than hemicelluloses and celluloses, which have maximum peaks at 270 and $360^{\circ} \mathrm{C}$, respectively. ${ }^{[39,40]}$ One of the reasons why lignin degradation occurs in a broader range of temperature is due to the different compounds the polymer forms under pyrolysis conditions. At temperatures between 350 and $450^{\circ} \mathrm{C}$, phenol groups on the lignin structure are pyrolyzed and converted to pyrocatechols. ${ }^{[41]}$ Additionally, at temperatures between 500 and $600^{\circ} \mathrm{C}$, secondary reactions occur due to the decomposition of lignin intermediates. ${ }^{[40]}$

The two most important parameters that should be analyzed after the thermogravimetric analyses are the $T_{\max }$, which is the maximum temperature value of the derivative curve $(d m / d T)$, and the $T_{\text {onset, that is }}$ defined as the temperature at which the loss mass becomes more apparent. ${ }^{[10]}$ Since lignin decomposes over a broad range and is less reactive in inert atmospheres, ${ }^{[42]}$ it should increase the thermal stability of 

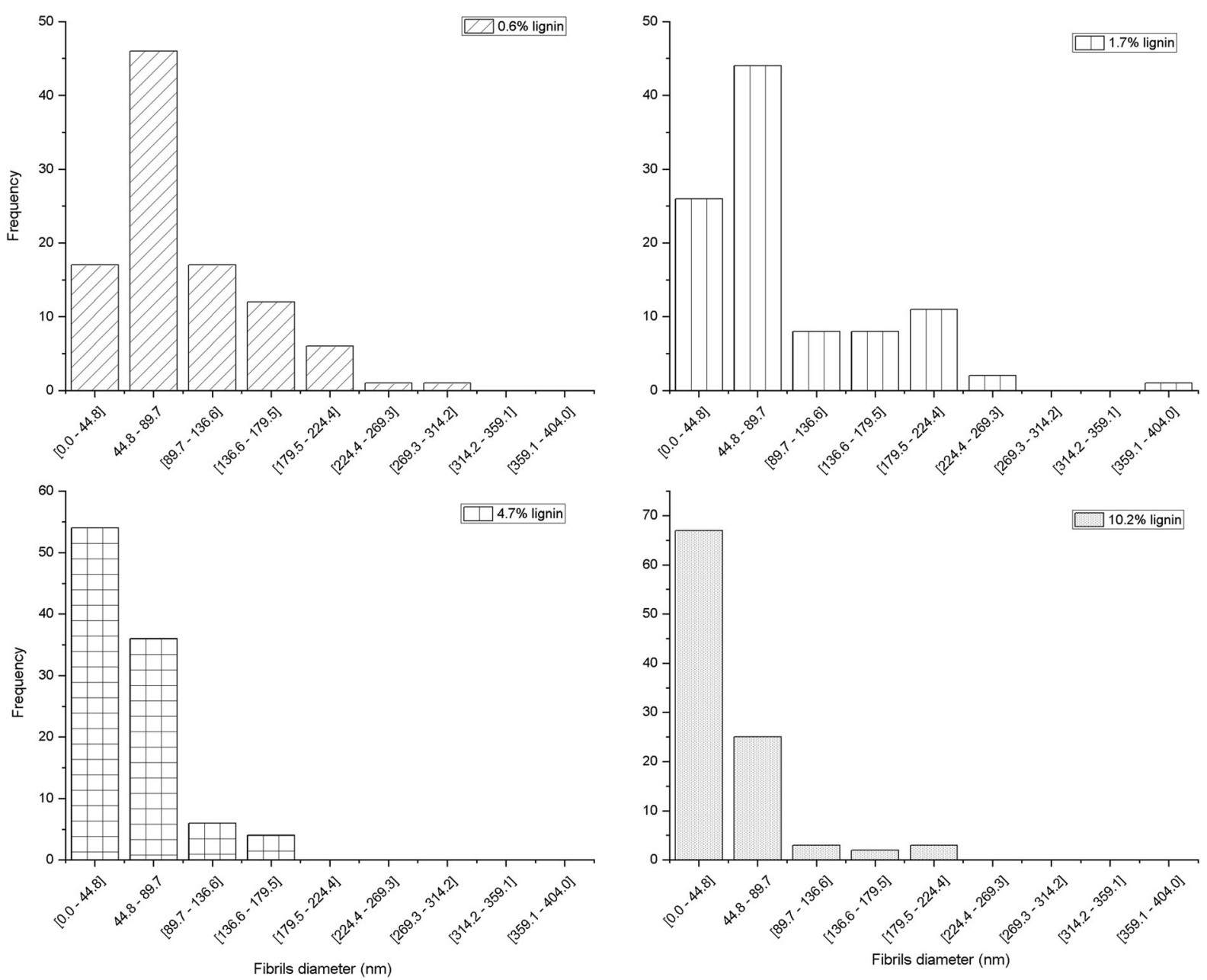

Figure 4. Diameters distribution for LCNF samples containing (a) 0.6 , (b) 1.7 , (c) 4.7 , and (d) $10.2 \%$ of lignin.

nanocellulose, but its presence did not show an improvement in the thermal properties.

Thermal behaviors were very similar between samples, with a $T_{\text {onset }}$ around $308^{\circ} \mathrm{C}$ and a $T_{\max }$ about $340^{\circ} \mathrm{C}$. Our results are consistent with those reported by Herrera et al. ${ }^{[34]}$ where no thermal improvements were observed at different lignin contents of the samples.

\section{Fourier-transform infrared spectroscopy with attenu- ated total reflectance accessory (ATR-FTIR)}

Figure 2 shows the FTIR spectra for the LCNF samples. The spectra were normalized by taking as reference the most pronounced peak at $1029 \mathrm{~cm}^{-1}$ which correspond to the $\mathrm{C}-\mathrm{O}$ stretching vibration of lignin and polysaccharides. All the spectra are very similar, since no chemical treatment was performed on the cellulose nanofibrils. A more detailed comparison (not shown here) demonstrated that the aromatic and aliphatic O$\mathrm{H}$ stretching vibrations (around $3324 \mathrm{~cm}^{-1}$ ) were less intense at the highest lignin content. This difference could be attributed to the reduction of the free $-\mathrm{OH}$ groups as the lignin content increases. ${ }^{[43]}$ The peak located between at $2901 \mathrm{~cm}^{-1}$ corresponds to C-H stretching due to aliphatic and aromatic structures. ${ }^{[39]}$ Analyzing the fingerprint region, at $1595 \mathrm{~cm}^{-1}$ there is an absorbance peak where the samples containing high lignin present a small shoulder on the left side corresponding to the aromatic skeletal vibrations from the presence of lignin together with $\mathrm{C}=\mathrm{O}$ stretching. ${ }^{[4]}$ The absorption peaks at 1423,1373 , and $1318 \mathrm{~cm}^{-1}$ are the result of $\mathrm{CH}_{2}, \mathrm{C}-\mathrm{H}$, and $\mathrm{O}-\mathrm{H}$ deformations respectively, ${ }^{[45]}$ at which sample containing $1.7 \%$ lignin shows the higher intensity peaks. Phenolic groups can cause $\mathrm{OH}$ deformation and this could be assigned to the peak at $1265 \mathrm{~cm}^{-1}$ which is more pronounce for sample containing $10.2 \%$ lignin. ${ }^{[43]}$ At lower wavenumbers, absorbance peaks appearing at $1165 \mathrm{~cm}^{-1}$ are the result of C$\mathrm{O}-\mathrm{C}$ stretching due to the presence of the pyranose ring on the cellulose fiber structure; peaks at 1104 and $1029 \mathrm{~cm}^{-1}$ correspond to $\mathrm{C}-\mathrm{OH}$ stretching, ${ }^{[39]}$ and $\mathrm{C}-\mathrm{O}$ stretching vibrations of lignin and polysaccharides. ${ }^{[4]}$ Finally, the absorbance peak at $897 \mathrm{~cm}^{-1}$ is associated with C-C stretching. ${ }^{[39]}$ 


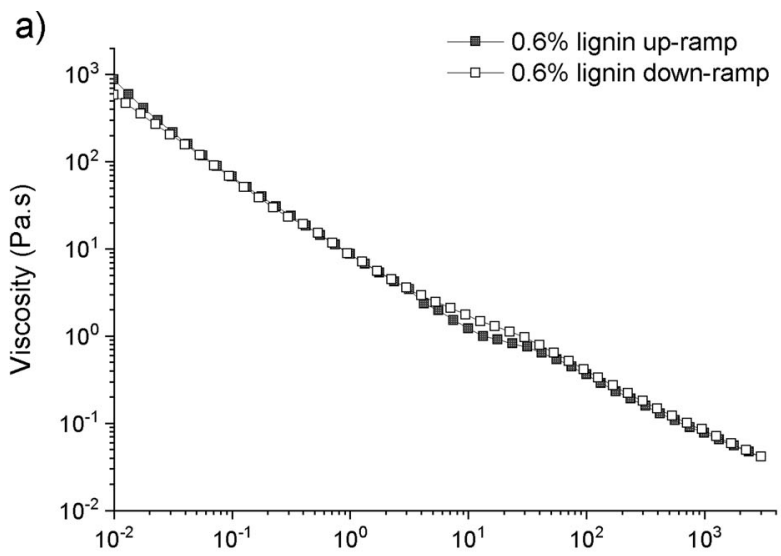

C)

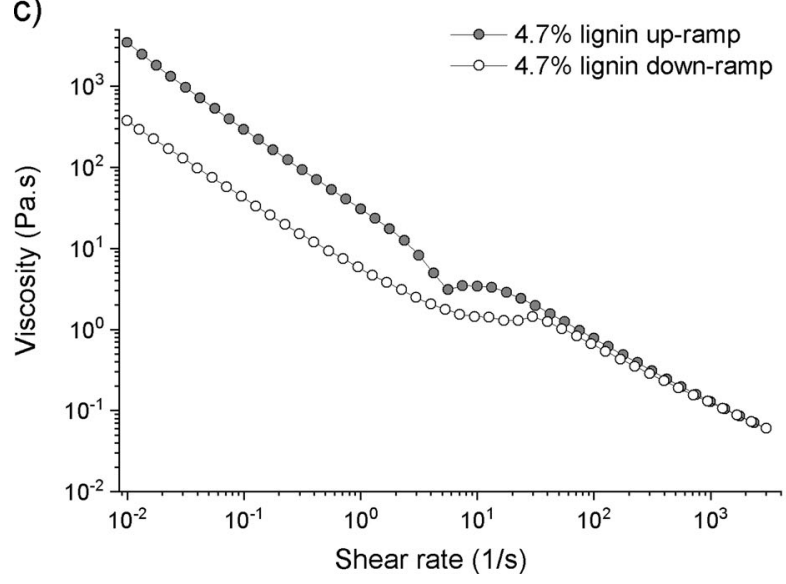

Figure 5. Steady state flow curves for LCNFs shear rate ramping

\section{Microscopy}

Morphology of the samples was studied by using Scanning Electron Microscopy (SEM) and AFM. SEM images were obtained at a magnification of $5000 \times$, allowing the visualization of the fibrillar structure of the nanofibrillated celluloses (see Figure S2, Supporting material).

AFM images were obtained in tapping mode. The presence of globular-shape particles was observed in the topographic images (Figure 3) and they were confirmed on the SEM images (See Figure S2, Supporting material). Similar structures have been reported in the literature $^{[4,34,46]}$ and it has been suggested that those globular structures may correspond to lignin nanoparticles that may be located over the fiber surface and between the fibrils. ${ }^{[12]}$ Although there is no conclusive data to confirm that these globular particles are indeed lignin nanoparticles, the amount of these globular nanoparticles increases as the lignin content of the samples increases. Future analysis is required to confirm the chemical composition of these samples and to determine whether they are indeed lignin particles (i.e., nanoTA, XPS, and Tof-SIMS).

To analyze the diameter distributions of the fibrils based on the different lignin contents, AFM images b)

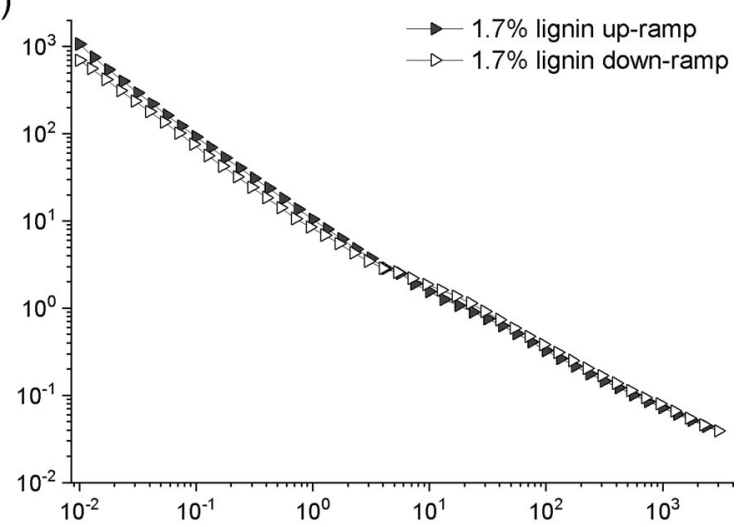

d)

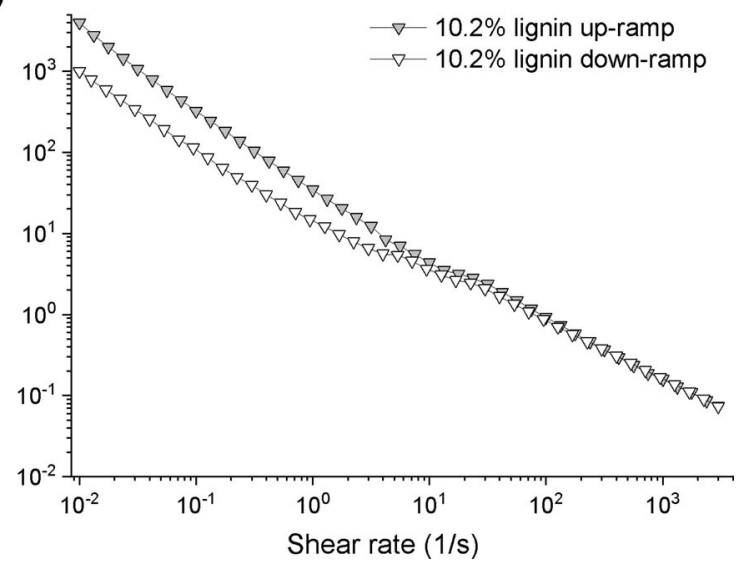

(a) UP curves, and (b) DOWN curves showing hysteresis.

were collected from five different zones of the coated surfaces. Diameters from 100 fibrils from each sample were quantified using the Image J Software. As can be seen in Figure 4, the fibril diameters are not homogeneous, thus, the distribution of diameters were grouped in nine different ranges where the majority of the sample's diameters are in a range from 0.0 to $44.8 \mathrm{~nm}$.

As the lignin content of the samples increase, fibrils diameters become smaller. For the range $[0.0-44.8] \mathrm{nm}$, which has the highest amount of fibrils, the mean fibril diameter and standard deviations were $34.3 \pm 8.7, \quad 33.6 \pm 9.2, \quad 27.5 \pm 10.2$, and $20.2 \pm 9.8 \mathrm{~nm}$ for samples containing $0.6,1.7,4.7$, and $10.2 \%$ of lignin, respectively. Similar behaviors have been reported on the literature. Rojo et al. ${ }^{[4]}$ supported this result by the antioxidant property of lignin, which is able to stabilize the cellulosic mechanoradicals formed during the mechanical process, avoiding the crosslink of the cellulose fibers. ${ }^{[1]}$ As the amount of lignin present on the LCNF increases, the possibility of attraction between the cellulose fibrils decreases, favoring the separation of the fibers. Consequently, smaller fibril diameters are obtained at higher lignin contents. 


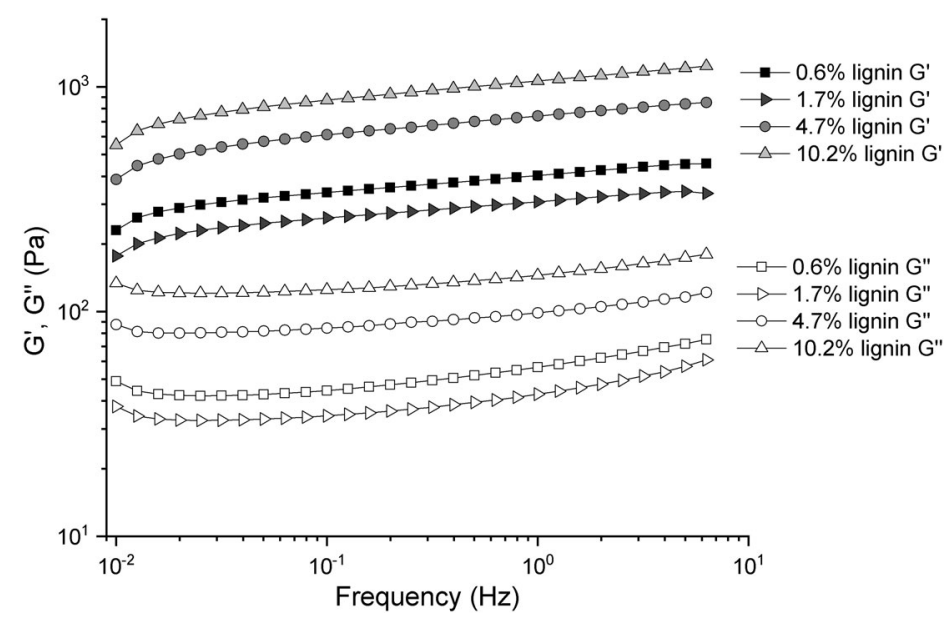

Figure 6. Oscillatory frequency sweeps for LCNF samples with an applied stress of $5 \mathrm{~Pa}$. $\mathrm{G}^{\prime}$ (bold), $\mathrm{G}^{\prime \prime}$ (empty) for $0.6 \%$ lignin ( $\mathbf{\square}$, $\square), 1.7 \%$ lignin $(\boldsymbol{\nabla}, \triangleright), 4.7 \%$ lignin $(\mathbf{O}, \circ)$, and $10.2 \%$ lignin $(\mathbf{\Lambda}, \triangle)$.

\section{Rheological behavior}

Viscous behavior of LCNF samples were successfully assessed by rheological measurements, with all specimens adjusted to $\mathrm{pH}=7$. All samples demonstrated a non-Newtonian shear-thinning behavior, where a decrease in the viscosity was accompanied by an increase in the shear rate. The shear thinning behavior observed in this study is in agreement with that reported in the literature. ${ }^{[17,22,23,27]}$

By closely studying the flow curves (Figure 5) it is clear that the viscosity of the samples is correlated to the amount of lignin. Analyzing the up-ramp, at low shear rates, samples containing 10.2 and $4.7 \%$ lignin show the highest viscosity values when compared with the other samples. All flow curves in the up-ramp exhibit a transitional behavior near $10 \mathrm{~s}^{-1}$. However, at shear rates below this transition, specimens with 10.2 and $4.7 \%$ lignin respectively, exhibit a remarkable change on the viscosity, followed by the highest viscosity values in the high shear rate region. In contrast, the two lowest lignin content specimens (0.6 and $1.7 \%)$ exhibit minor change after the transition, and generally, they appear nearly identical across the entire flow curve.

When analyzing the up- and down-ramp flow curve cycles for each sample, substantial hysteresis occurred in samples containing higher amounts of lignin; the starting and ending viscosities differed by nearly one order of magnitude.

Particularly for the specimen containing $4.7 \%$ lignin, the up-ramp shows an abrupt transition from shear thinning to shear thickening near $3 \mathrm{~s}^{-1}$. The corresponding down-ramp exhibits a more gradual transition starting near $20 \mathrm{~s}^{-1}$. The behavior shown in Figure 5c) was reproducible, and perhaps indicates lignin-lignin interactions modulated by the degree of shear rate-dependent fibril orientation. For instance, during the up-ramp, near $3 \mathrm{~s}^{-1}$, perhaps the fibrils achieve a critical degree of alignment such that lignin-lignin interactions (on separate fibrils) become optimal, and these interactions persist as normal shear-thinning advances at higher shear rates. Likewise, in the down ramp, as the shear rate declines, the fibrils tend toward less alignment such that lignin-lignin interactions are broken. If this interpretation is correct, then it is apparent that the optimization of lignin-lignin interactions (up-ramp) is relatively sudden, and their disruption (downramp) occurs more gradually. Furthermore, since the high lignin-content samples exhibited substantial hysteresis, this hypothesis implies that some less than optimal lignin-lignin interactions where present at the beginning of the up-ramp; but ultimately, they were mostly disrupted as indicated by the hysteresis. Perhaps the abrupt behavior exhibited by the $4.7 \%$ lignin sample reflects a critical dimensional scale of the lignin structures and/or inter-fibril distances (under the $\mathrm{pH}$ and solids content employed here). Additional experimentation is required to test this hypothesis, and in any case, it appears that residual lignin, even at very low levels, causes a detectable fibril association over a similar shear rate range in the up- and down ramp.

Power-law parameters and regression values $\left(R^{2}\right)$ were calculated for the fitted-UP curves, which are shown in Table 1. According to the literature, almost all non-Newtonian fluids have a power index $<1$ meaning that they follow a shear-thinning behavior, ${ }^{[24]}$ which can be confirmed for all the samples containing lignin since they have power indexes $<0.3$. All the $R^{2}$ values were very close to 1 indicating that fitting the data with the power-law model is a good 
approximation. Similar results were reported for bleached cellulose nanofibril suspensions. ${ }^{[47]}$

Frequency sweep curves are useful for studying the viscoelastic nature of the samples, which is determined based on the magnitude of the storage moduli $\left(G^{\prime}\right)$ compared to the loss moduli $\left(G^{\prime \prime}\right){ }^{[48]}$ As can be seen in Figure 6 for all LCNF samples, $G^{\prime}$ is larger than $G^{\prime \prime}$ across the entire frequency range, which confirms a gel-like behavior of the samples. As a general behavior, there is a clear relation between the lignin content and the values of $G^{\prime}$ and $G^{\prime \prime}$, indicating that as the lignin content increases, $G^{\prime}$ and $G^{\prime \prime}$ increase. Considering the solid content of the samples is the same, then for samples with higher lignin content, we observed a smaller diameter of the fibrils, suggesting that there would be a greater number of fiber-fiber contacts, forming a tighter network that would exhibit a higher storage modulus. However, it can be observed that sample containing $0.6 \%$ lignin presents slightly higher $G^{\prime}$ and $G^{\prime \prime}$ values than sample $1.7 \%$ lignin. These differences may be attributed to the bleaching process utilizing hydrogen peroxide, where side groups can be formed, remaining on the structure ${ }^{[49]}$ and affecting, as a result, the rheological properties of the samples. Nevertheless, this hypothesis requires an additional and more in-deep analysis which exceeds the scope of this article.

No pre-shear was applied in these measurements. After $10 \mathrm{~Hz}$, the inertial effects start affecting the acquisition of the data limiting the range of measurement from 0.01 to $10 \mathrm{~Hz}$.

\section{Conclusions}

In this work we have extensively analyzed how the chemical composition of LCNF samples, particularly the amount of lignin and hemicelluloses, is related with their characteristics, in order to further understand the rheological behavior of the samples.

Although lignin is considered to be the binder of the cellulose fiber structure, holding together cellulose and hemicellulose, analyzing the fibril diameter size distribution suggests that its presence improves the defibrillation of the samples. Also, using SEM and AFM confirmed that after defibrillation process globular spheres, remained on the colloidal suspension mixed with the nanofibrils. Nevertheless, further analyses are required to confirm if they correspond to lignin spheres.

Rheological behavior was effectively assessed, showing an increase of the viscosity as the lignin content increased, which corroborated the shear-thinning behavior of LCNFs. Besides, strong interactions between fibrils-lignin and lignin-lignin are suggested due to the irreversible hysteresis curve obtained during the rheological analysis.

No increasing on thermal degradation temperature of the samples were observed at different lignin contents by thermogravimetric analysis.

From an analysis of all the performed characterization techniques, it can be concluded that LCNF particles present very intriguing properties that should be further studied. By fully understanding their intrinsic properties, they could be considered for different applications. Additionally, their ease of production when compared with fully bleached cellulose nanofibrils gives LCNF fibers.

\section{Acknowledgments}

The authors would like to thank Dr. Iris B. Vega for very useful scientific discussions and guidance, and Dr. Orlando Rojas (Aalto University) for granting the access to AFM facilities.

\section{Funding}

This publication was supported by the Forest Service Sponsored Program (17-JV-11330131-006), the Alabama Agricultural Experiment Station, and the Hatch program of the National Institute of Food and Agriculture (ALA013-117003), United States Department of Agriculture. School of Forestry and Wildlife Sciences at Auburn University financial support to complete this work is greatly appreciated.

\section{References}

[1] Mirmehdi, S.; de Oliveira, M. L. C.; Hein, P. R. G.; Dias, M. V.; Sarantópoulos, C. I. G.; de, L.; Tonoli, G. H. D. Spraying Cellulose Nanofibrils for Improvement of Tensile and Barrier Properties of Writing \& Printing (W\&P) Paper. J. Wood Chem. Technol. 2018, 38, 233-245. doi:10.1080/02773813. 2018.1432656.

[2] Liu, C.; Du, H.; Dong, L.; Wang, X.; Zhang, Y.; Yu, G.; Li, B.; Mu, X.; Peng, H.; Liu, H. Properties of Nanocelluloses and Their Application as Rheology Modifier in Paper Coating. Ind. Eng. Chem. Res. 2017, 56, 8264-8273. doi:10.1021/acs.iecr.7b01804.

[3] Spence, K. L.; Venditti, R. A.; Rojas, O. J.; Habibi, Y.; Pawlak, J. J. The Effect of Chemical Composition on Microfibrillar Cellulose Films from Wood Pulps: Water Interactions and Physical Properties for Packaging Applications. Cellulose 2010, 17, 835-848. doi:10.1007/s10570-010-9424-8.

[4] Rojo, E.; Peresin, M. S.; Sampson, W. W.; Hoeger, I. C.; Vartiainen, J.; Laine, J.; Rojas, O. J. Comprehensive Elucidation of the Effect of Residual 
Lignin on the Physical, Barrier, Mechanical and Surface Properties of Nanocellulose Films. Green Chem. 2015, 17, 1853-1866. doi:10.1039/C4GC02398F.

[5] Cunha, A. G.; Mougel, J.-B.; Cathala, B.; Berglund, L. A.; Capron, I. Preparation of Double Pickering Emulsions Stabilized by Chemically Tailored Nanocelluloses. Langmuir 2014, 30, 9327-9335. doi:10. 1021/la5017577.

[6] Bian, H.; Chen, L.; Dai, H.; Zhu, J. Y. Effect of Fiber Drying on Properties of Lignin Containing Cellulose Nanocrystals and Nanofibrils Produced through Maleic Acid Hydrolysis. Cellulose 2017, 24, 4205-4216. doi:10.1007/s10570-017-1430-7.

[7] Klemm, D.; Kramer, F.; Moritz, S.; Lindström, T.; Ankerfors, M.; Gray, D.; Dorris, A. Nanocelluloses: A New Family of Nature-Based Materials. Angew. Chem. Int. Ed. Engl. 2011, 50, 5438-5466. doi:10.1002/anie. 201001273.

[8] Solala, I.; Iglesias, M. C.; Peresin, M. S. On the Potential of Lignin-Containing Cellulose Nanofibrils (LCNF): A Review on Properties and Applications. Cellulose 2019, doi:10.1007/s10570-019-02899-8).

[9] Suopajärvi, T.; Liimatainen, H.; Niinimäki, J. Morphological Analyses of Some Micro- and Nanofibrils from Birch and Wheat Straw Sources. J. Wood Chem. Technol 2015, 35, 102-112. doi:10.1080/ 02773813.2014.892990.

[10] Nair, S. S.; Kuo, P.-Y. Y.; Chen, H.; Yan, N. Investigating the Effect of Lignin on the Mechanical, Thermal, and Barrier Properties of Cellulose Nanofibril Reinforced Epoxy Composite. Ind. Crops Prod 2017, 100, 208-217. doi:10.1016/j.indcrop.2017. 02.032 .

[11] Solala, I.; Volperts, A.; Andersone, A.; Dizhbite, T.; Mironova-Ulmane, N.; Vehniäinen, A.; Pere, J.; Vuorinen, T. Mechanoradical Formation and Its Effects on Birch Kraft Pulp during the Preparation of Nanofibrillated Cellulose with Masuko Refining. Holzforschung 2012, 66 (4), 477-483. doi:10.1515/hf. 2011.183.

[12] Lê, H. Q.; Dimic-Misic, K.; Johansson, L.; Maloney, T.; Sixta, H. Effect of Lignin on the Morphology and Rheological Properties of Nanofibrillated Cellulose Produced from $\gamma$-Valerolactone/Water Fractionation Process. Cellulose 2018, 25, 179-194. doi:10.1007/ s10570-017-1602-5.

[13] Herzele, S.; Veigel, S.; Liebner, F.; Zimmermann, T.; Gindl-Altmutter, W. Reinforcement of Polycaprolactone with Microfibrillated Lignocellulose. Ind. Crops Prod. 2016, 93, 302-308. doi:10.1016/j. indcrop.2015.12.051.

[14] Ferrer, A.; Hoeger, I. C.; Lu, X.; Rojas, O. J. Reinforcement of Polypropylene with Lignocellulose Nanofibrils and Compatibilization with Biobased Polymers. J. Appl. Polym. Sci. 2016, 133, 43854. doi:10. 1002/app.43854.

[15] Ballner, D.; Herzele, S.; Keckes, J.; Edler, M.; Griesser, T.; Saake, B.; Liebner, F.; Potthast, A.; Paulik, C.; Gindl-Altmutter, W. Lignocellulose NanofiberReinforced Polystyrene Produced from Composite Microspheres Obtained in Suspension Polymerization Shows Superior Mechanical Performance. ACS Appl.
Mater. Interfaces. 2016, 8, 13520-13525. doi:10.1021/ acsami.6b01992.

[16] Hubbe, M. A.; Ferrer, A.; Tyagi, P.; Yin, Y.; Salas, C.; Pal, L.; Rojas, O. J. Nanocellulose in Thin Films, Coatings, and Plies for Packaging Applications: A Review. BioResources 2017, 12, 2143-2233. pp . doi:10. 15376/biores.12.1.2143-2233.

[17] Pääkkö, M.; Ankerfors, M.; Kosonen, H.; Nykänen, A.; Ahola, S.; Osterberg, M.; Ruokolainen, J.; Laine, J.; Larsson, P. T.; Ikkala, O.; Lindström, T. Enzymatic Hydrolysis Combined with Mechanical Shearing and High-Pressure Homogenization for Nanoscale Cellulose Fibrils and Strong Gels. Biomacromolecules 2007, 8, 1934-1941. doi:10.1021/bm061215p.

[18] Benhamou, K.; Dufresne, A.; Magnin, A.; Mortha, G.; Kaddami, H. Control of Size and Viscoelastic Properties of Nanofibrillated Cellulose from Palm Tree by Varying the TEMPO-Mediated Oxidation Time. Carbohydr. Polym. 2014, 99, 74-83. doi:10.1016/j. carbpol.2013.08.032.

[19] He, M.; Yang, G.; Chen, J.; Ji, X.; Wang, Q. Production and Characterization of Cellulose Nanofibrils from Different Chemical and Mechanical Pulps. J. Wood Chem. Technol. 2018, 38, 149-158. doi: 10.1080/02773813.2017.1411368.

[20] Naderi, A.; Lindström, T.; Sundström, J. Carboxymethylated Nanofibrillated Cellulose: Rheological Studies. Cellulose 2014, 21, 1561-1571. doi:10.1007/s10570-014-0192-8.

[21] Gong, G. Rheological Properties of Nanocellulose Material. In Handbook of Green Material; Kristiina, O., Aji, P. M., Pia, Q., Alexander, B., Orlando, R., Mohini, S., Eds.; World Scientific: Singapore, 2014; pp: $139-157$.

[22] Karppinen, A.; Vesterinen, A. H.; Saarinen, T.; Pietikäinen, P.; Seppälä, J. Effect of Cationic Polymethacrylates on the Rheology and Flocculation of Microfibrillated Cellulose. Cellulose 2011, 18, 1381-1390. doi:10.1007/s10570-011-9597-9.

[23] Tanaka, R.; Saito, T.; Hondo, H.; Isogai, A. Influence of Flexibility and Dimensions of Nanocelluloses on the Flow Properties of Their Aqueous Dispersions. Biomacromolecules 2015, 16, 2127-2131. doi:10.1021/ acs.biomac.5b00539.

[24] Macosko, C. W. Rheology: Principle, Measurements, and Applications; Wiley-VCH Verlag GmbH \&Co.: Canada, 1994. doi:10.1007/978-3-642-55409-4..

[25] Hubbe, M. A.; Rojas, o. J.; Lucia, L.; Sain, M. Cellulosic Nanocomposites: A Review. BioResources 2008, 3, 929-980. doi:10.15376/biores.3.3.929-980..

[26] Agoda-Tandjawa, G.; Durand, S.; Berot, S.; Blassel, C.; Gaillard, C.; Garnier, C.; Doublier, J. L. Rheological Characterization of Microfibrillated Cellulose Suspensions after Freezing. Carbohydr. Polym. 2010, 80, 677-686. doi:10.1016/j.carbpol.2009.11.045.

[27] Iotti, M.; Gregersen, Ø. W.; Moe, S.; Lenes, M. Rheological Studies of Microfibrillar Cellulose Water Dispersions. J. Polym. Environ. 2011, 19, 137-145. doi:10.1007/s10924-010-0248-2.

[28] Li, M. C.; Wu, Q.; Song, K.; Qing, Y.; Wu, Y. Cellulose Nanoparticles as Modifiers for Rheology and Fluid Loss in Bentonite Water-Based Fluids. ACS 
Appl. Mater. Interfaces. 2015, 7, 5006-5016. doi:10. 1021/acsami.5b00498.

[29] Liu, Y.; Gordeyeva, K.; Bergström, L. Steady-Shear and Viscoelastic Properties of Cellulose NanofibrilNanoclay Dispersions. Cellulose 2017, 24, 1815-1824. doi:10.1007/s10570-017-1211-3.

[30] Iglesias, M. C.; Gomez-Maldonado, D.; Via, B. K.; Jiang, Z.; Peresin, M. S. Comparison of Kraft and Sulfite Pulping Processes and Their Effects on Cellulose Fibers and Nanofibrillated Cellulose Properties: A Review. For. Prod. J. 2019, 70, 10-21. doi:10.13073/FPJ-D-19-00038.

[31] Espinosa, E.; Tarrés, Q.; Delgado-Aguilar, M.; González, I.; Mutjé, P.; Rodríguez, A. Suitability of Wheat Straw Semichemical Pulp for the Fabrication of Lignocellulosic Nanofibres and Their Application to Papermaking Slurries. Cellulose 2016, 23, 837-852. doi:10.1007/s10570-015-0807-8.

[32] Horseman, T.; Tajvidi, M.; Diop, C. I. K.; Gardner, D. J. Preparation and Property Assessment of Neat Lignocellulose Nanofibrils (LCNF) and Their Composite Films. Cellulose 2017, 24, 2455-2468. doi: 10.1007/s10570-017-1266-1.

[33] Kimura, K.; Kikuchi, S.; Yamasaki, S. Accurate Root Length Measurement by Image Analysis. Plant Soil 1999, 216, 117-127. doi:10.1016/j.agwat.2007.03.002..

[34] Herrera, M.; Thitiwutthisakul, K.; Yang, X.; Rujitanaroj, P.; On, Rojas, R.; Berglund, L. Preparation and Evaluation of High-Lignin Content Cellulose Nanofibrils from Eucalyptus Pulp. Cellulose 2018, 25, 3121-3133. doi:10.1007/s10570-018-1764-9.

[35] Delgado-Aguilar, M.; González, I.; Tarrés, Q.; Pèlach, M. A.; Alcalà, M.; Mutjé, P. The Key Role of Lignin in the Production of Low-Cost Lignocellulosic Nanofibres for Papermaking Applications. Ind. Crops Prod. 2016, 86, 295-300. doi:10.1016/j.indcrop.2016. 04.010.

[36] Espinosa, E.; Sánchez, R.; Otero, R.; DomínguezRobles, J.; Rodríguez, A. A Comparative Study of the Suitability of Different Cereal Straws for Lignocellulose Nanofibers Isolation. Int. J. Biol. Macromol. 2017, 103, 990-999. doi:10.1016/j.ijbiomac. 2017.05.156.

[37] Hult, E. L.; Iversen, T.; Sugiyama, J. Characterization of the Supermolecular Structure of Cellulose in Wood Pulp Fibres. Cellulose 2003, 10, 103-110. doi:10.1023/ A:1024080700873..

[38] Smook, G. Handbook for Pulp and Paper Technologists, 4th ed.; Kocurek M., Ed.; TAPPI Press: Georgia, 2016.
[39] Yang, H.; Yan, R.; Chen, H.; Lee, D. H.; Zheng, C. Characteristics of Hemicellulose, Cellulose and Lignin Pyrolysis. Fuel 2007, 86, 1781-1788. doi:10.1016/j.fuel. 2006.12.013.

[40] Brebu, M.; Vasile, C. Thermal Degradation of Lignin-A Review. Cellul. Chem. Technol. 2010, 44, 353-363.

[41] Murwanashyaka, J. N.; Pakdel, H.; Roy, C. Step-Wise and One-Step Vacuum Pyrolysis of Birch-Derived Biomass to Monitor the Evolution of Phenols. J. Anal. Appl. Pyrol. 2001, 60, 219-231. doi:10.1016/S01652370(00)00206-0.

[42] Vänskä, E.; Vihelä, T.; Peresin, M. S.; Vartiainen, J.; Hummel, M.; Vuorinen, T. Residual Lignin Inhibits Thermal Degradation of Cellulosic Fiber Sheets. Cellulose 2016, 23, 199-212. doi:10.1007/s10570-0150791-z.

[43] Diop, C. I. K.; Tajvidi, M.; Bilodeau, M. A.; Bousfield, D. W.; Hunt, J. F. Isolation of Lignocellulose Nanofibrils (LCNF) and Application as Adhesive Replacement in Wood Composites: Example of Fiberboard. Cellulose 2017, 24, 3037-3050. doi:10. 1007/s10570-017-1320-z.

[44] Huang, Y.; Wang, Z.; Wang, L.; Chao, Y.; Akiyama, T.; Yokoyama, T.; Matsumoto, Y. Analysis of Lignin Aromatic Structure in Wood Fractions Based on IR Spectroscopy. J. Wood Chem. Technol. 2016, 36, 377-382. doi:10.1080/02773813.2016.1179325.

[45] Larkin, P. J.; Unknown, I. R.; Spectra, R. In IR and Raman Spectroscopy - Principles and Spectral Interpretation; Elsevier: United States, 2011; pp 177-212. doi:10.1016/b978-0-12-386984-5.10001-1..

[46] Bian, H.; Chen, L.; Dai, H.; Zhu, J. Y. Integrated Production of Lignin Containing Cellulose Nanocrystals (LCNC) and Nanofibrils (LCNF) Using an Easily Recyclable Di-Carboxylic Acid. Carbohydr. Polym. 2017, 167, 167-176. doi:10.1016/j.carbpol.2017. 03.050 .

[47] Nazari, B.; Kumar, V.; Bousfield, D. W.; Toivakka, M. Rheology of Cellulose Nanofibers Suspensions: Boundary Driven Flow. J. Rheol. (N. Y. N. Y) 2016 60, 1151-1159. doi:10.1122/1.4960336.

[48] Hubbe, M. A.; Tayeb, P.; Joyce, M.; Tyagi, P.; Kehoe, M.; Dimic-Misic, K.; Pal, L. Rheology of Nanocellulose-Rich Aqueous Suspensions: A Review. BioResources 2017, 12, 9556-9661. doi:10.15376/biores. 12.4. Hubbe.

[49] Zeronian, S. H.; Inglesby, M. K. Bleaching of Cellulose by Hydrogen Peroxide. Cellulose 1995, 2, 265-272. doi:10.1007/BF00811817. 